\title{
Influence of Subway Shield Tunnel Construction on Ground Settlement
}

\author{
Yilei Zhang ${ }^{1}$, Jianxun $\mathrm{Ma}^{1 *}$, Dan Cheng ${ }^{1}$, Wenxiao $\mathrm{Li}^{1}$ \\ ${ }^{1}$ School of Human Settlements and Civil Engineering, Xi'an Jiaotong University, Xian, China
}

\begin{abstract}
Shield construction has the advantages of stable driving speed, saving manpower, and being able to carry out construction in complex strata, which has been more and more widely used. In the process of shield construction, there is a gap between shield body and segment, which is easy to cause ground settlement when the grouting speed cannot keep up. This paper summarizes the common methods to predict the surface settlement, analyzes the causes of the settlement, and lists an engineering case to illustrate the factors affecting the surface settlement. Finally, it comes to the conclusion that the main causes of the surface settlement caused by shield tunnel construction are formation loss and consolidation settlement, and the use of small cutterhead and composite cutterhead can reduce the surface settlement, It provides a reference for the development of shield construction.
\end{abstract}

\section{Introduction}

With the continuous development of economy and the increasing size of population, the urban traffic pressure is increasing, resulting in a series of problems such as traffic congestion, environmental pollution and so on. Ground transportation has been unable to meet people's daily travel needs. Subway has become an important mode of transportation in many cities because of its fast, convenient and less pollution.

Although the development of subway has been for a long time, and the technical level has been greatly improved, the common construction methods mainly include open cut method, subsurface excavation method and shield method. Shield method has been more and more widely used because of its many advantages. In the process of shield construction, it is inevitable to have different degrees of influence on the soil layer, and then cause the surface settlement. Excessive displacement will cause structural damage and other adverse effects. Therefore, it is of great significance to control the surface settlement in the construction process. In the process of shield construction, the selection of shield parameters will have an important impact on the surface settlement, so the selection of reasonable shield parameters can reduce the difficulty of the whole construction process. The common parameters are cutterhead torque and cutterhead form, so it is of great significance to study the relationship between them and surface settlement.

\section{Prediction method of ground settlement}

The influence of surface settlement on the construction process is extremely critical. The correct prediction of settlement value can avoid a series of accidents. At present, the commonly used methods include empirical method, model test method, analytic method and numerical simulation method. The advantages and disadvantages of various methods are shown in Table 1.

Table1. Advantages and disadvantages of different research

\begin{tabular}{|c|c|c|}
\hline $\begin{array}{c}\text { Method } \\
\text { Name }\end{array}$ & Advantage & Disadvantages \\
\hline $\begin{array}{c}\text { Empirical } \\
\text { Method }\end{array}$ & $\begin{array}{c}\text { the method is } \\
\text { simple and } \\
\text { intuitive }\end{array}$ & $\begin{array}{c}\text { the calculation method is } \\
\text { rough and difficult to } \\
\text { reflect the actual } \\
\text { situation }\end{array}$ \\
\hline $\begin{array}{c}\text { Model Test } \\
\text { Method }\end{array}$ & $\begin{array}{c}\text { the mechanism } \\
\text { is easy to } \\
\text { express } \\
\text { it needs a lot of } \\
\text { resources, and there is a } \\
\text { certain deviation } \\
\text { between the model and } \\
\text { the actual situation }\end{array}$ \\
\hline $\begin{array}{c}\text { Analytic } \\
\text { Method }\end{array}$ & $\begin{array}{c}\text { the theoretical } \\
\text { solution can be } \\
\text { obtained with } \\
\text { less calculation }\end{array}$ & $\begin{array}{c}\text { only in a few cases can } \\
\text { the theoretical solution } \\
\text { be obtained }\end{array}$ \\
\hline $\begin{array}{c}\text { Numerical } \\
\text { Simulation } \\
\text { Method }\end{array}$ & $\begin{array}{c}\text { there are many } \\
\text { options }\end{array}$ & $\begin{array}{c}\text { lack of consideration of } \\
\text { practical factors }\end{array}$ \\
\hline
\end{tabular}

\footnotetext{
*Jianxun Ma: majx@xjtu.edu.cn
} 


\subsection{Empirical method}

The empirical method is mainly to analyze and fit the field measured data to get the empirical formula and apply it to the actual project for verification. Peck formula is the most famous one. Peck ${ }^{[1]}$ puts forward this classic settlement formula on the basis of a large number of measured data. This formula plays an extremely important role in the analysis of land subsidence. After continuous improvement and correction, peck formula has been widely used. The expression is as follows:

$$
\begin{gathered}
S(x)=S_{\max }(x) \exp \left(-\frac{x^{2}}{2 i^{2}}\right) \\
S_{\max }=\frac{V_{\text {loss }}}{i \sqrt{2 \pi}}=\frac{\pi R^{2} \eta}{i \sqrt{2 \pi}} \\
i=\frac{Z_{0}}{\sqrt{2 \pi} \tan \left(45^{0}-\frac{\varphi}{2}\right)}
\end{gathered}
$$

Where, $\mathrm{X}$-Distance from the center of the tunnel, $\mathrm{m}$; $\mathrm{S}(\mathrm{x})$ - Surface subsidence value related to $\mathrm{X}, \mathrm{m} ; \mathrm{S}_{\max }-$ Maximum settlement of tunnel center line, $m$; $i$-Width coefficient of settling tank; $\mathrm{V}_{\text {loss }}$-Formation volume loss per unit length, $\mathrm{m}^{3} / \mathrm{m} ; \mu$-Surface loss rate related to engineering geological conditions and other factors; RTunnel radius,m.

\subsection{Model test method}

Model test method is a convenient and effective construction method, which combines the field measured data with the theoretical research, simulates the construction situation in the laboratory, and then analyzes a series of possible situations.

Atkinson ${ }^{[2]}$ carried out centrifugal experiments on shallow tunnels in the environment of clay and sand. Based on a lot of analysis, the stress-strain relationship causing tunnel failure was obtained, and the relevant analytical solution of surface settlement under the plastic theory was proposed.

Imamura ${ }^{[3]}$ carried out the simulation test of tunnel excavation process, set different thickness of overburden on the top of the tunnel to study the trend of surface deformation under different earth pressures. After indepth analysis, it is found that the relationship between surface settlement and overburden thickness is in the form of exponential function.

\subsection{Analytic method}

The analytical method is to combine the theory and numerical calculation methods to study the variation law of surface settlement in the process of shield tunnel construction, and then deduce the theoretical calculation formula.

Sagaseta ${ }^{[4]}$ applied the image analysis method to the construction of shield tunnel, obtained the calculation formula of three-dimensional stress field for calculating the surface deformation, and took the displacement value of soil deformation as a variable to analyze the strain field at a certain depth below the ground, and obtained good practical effect.

Liu Baochen ${ }^{[5]}$ applied the stochastic medium prediction theory to the surface settlement prediction of subway shield construction, obtained two-dimensional and three-dimensional surface settlement prediction methods, compiled a set of computer program for calculating deformation, and verified the reliability of the program through some examples.

\subsection{Numerical simulation method}

With the rapid development of computer, many engineering problems can be solved more accurately. Modeling and analyzing the actual project can provide great convenience for construction.

Li Hongbo ${ }^{[6]}$. Analyzed the ground settlement during shield tunneling, modeled the subway construction with ANSYS, and numerically simulated the settlement at different excavation stages with FLAC 3D, and analyzed the influence of time and space effects on ground settlement during shield tunneling.

Du Mingfang ${ }^{[7]}$ used Midas to analyze the ground settlement caused by the shield tunnel crossing the railway, and concluded that the ground settlement caused by the shield tunnel decreases with the increase of the distance from the center line of the tunnel, and the railway track can play a buffer role in the ground settlement.

\section{Mechanism analysis of ground settlement caused by shield tunnel construction}

\subsection{Causes of ground settlement caused by shield tunnel construction}

When the soil is soft, the shield construction will cause the soil around the excavation face to loosen or even collapse, and its intuitive performance is the surface settlement. The main reasons for the settlement of shield tunnel construction are the formation loss and consolidation settlement.

\subsubsection{Formation loss}

In the process of shield construction, due to its construction technology, the earthwork produced by shield construction is larger than that calculated according to the cross section, which will lead to a certain gap between the shield machine shell and the tunnel lining. When the construction stratum is relatively weak, the gap can be filled by the surrounding soil, which will cause the displacement of soil, and then lead to surface settlement.

The formation loss is the volume difference between the actual excavated earthwork and the calculated earthwork. Generally, the formation loss is divided into three categories: the normal formation loss caused by the geological conditions of the construction site or the selection of construction technology and other objective 
conditions; In the process of shield tunneling, the abnormal ground loss is caused by the wrong selection of machine parameters and the failure of grouting in time; In the process of shield tunneling, the disastrous ground loss caused by collapse of working face.

\subsubsection{Consolidation settlement}

In the process of tunnel shield construction, grouting and over excavation will change the original state of the stratum. Due to the disturbance, the surrounding soil will produce a certain excess pore water pressure. Under the action of this water pressure, the stratum will have a certain degree of settlement, which is called consolidation settlement. According to different pressures, consolidation settlement can be divided into primary consolidation settlement and secondary consolidation settlement. Due to the dissipation of excess pore water pressure, the pores between soil particles are reduced and the soil is compacted, and then the settlement is called primary consolidation settlement. The settlement caused by shear deformation of soil due to creep of soil skeleton is called secondary consolidation settlement.

The primary consolidation settlement is the main form of surface settlement, and with the increase of overburden thickness, the proportion of primary consolidation settlement is also increasing. When the tunnel depth is large, even if the total settlement is small, the proportion of main settlement can not be ignored. The duration of secondary consolidation settlement is generally long, which can last for several months or even years in the fluid plastic soil with large pores.

\subsection{Development process of surface subsidence}

The surface settlement caused by shield construction can be divided into five stages: initial settlement, excavation surface settlement, tail settlement, tail pore settlement and long term continuous settlement.

\subsubsection{Initial settlement}

When the shield machine has not reached the designated position, the settlement outside the sliding surface in front of the shield machine is called initial settlement. The main cause of initial settlement is consolidation settlement, which is largely caused by the change of stress state between soil due to the decrease of groundwater level during construction.

\subsubsection{Excavation ground settlement}

When the shield machine reaches the designated position, the settlement of the soil in front of the shield machine is called the excavation face settlement. The excavation forms of different tunnels are related to the type of shield, and the stress state of the soil at the excavation face is different due to the different shield parameters. The cause of settlement is that the vertical stress of the excavation face is too large. When it exceeds the thrust of the shield machine, the settlement occurs.

\subsubsection{Tail settlement}

When the excavation face of shield machine passes through the designated position, the settlement is called tail settlement. In the process of shield construction, there will be friction between the soil layer and the shield shell, which will produce a sliding surface. Shear stress is generated in the soil near the sliding surface. When the shield machine passes through the broken stratum, the soil will move to the pores generated by the shield machine under the action of shear force.

\subsubsection{Tail pore settlemen}

The settlement after shield tail passing is called tail pore settlemen. Due to the need of on-site construction and the certain thickness of shield shell, the outer diameter of shield is about $2 \%$ larger than that of tunnel lining. This will lead to a certain gap between the shield shell and the tunnel lining. If it can not be filled in time, it will cause the collapse of the surrounding soil.

\subsubsection{Long term continuous settlement}

The settlement that still exists for a long time after shield passing is called long term continuous settlement. This kind of settlement is related to construction quality, geological conditions and shield type.

\section{Measures to control ground settlement}

In the process of subway shield construction, ground settlement will be caused for various reasons. In order to ensure the smooth progress of construction, appropriate measures should be taken to control the ground settlement within a reasonable range. The following measures can be taken:

\subsection{Keep the excavation face stable}

Appropriate additives can be added in the shield construction to make the residue have sufficient fluidity and ensure the normal operation of the dumping facilities. When the soil layer is clay or silt, the internal friction angle is small and the water permeability is poor, so the spiral dumping device is needed to ensure the stability of the excavation face. For sand and gravel, due to its large internal friction angle and poor fluidity, appropriate additives must be added to reduce its permeability to meet the construction requirements.

\subsection{Grouting of shield tail gap}

Grouting should be done in time. When the exposure time of the tunnel lining exceeds a certain value, it will lead to the collapse of the tunnel. Therefore, in order to reduce the surface settlement, synchronous grouting must be done. The grouting amount should meet the requirements. Because the grouting material has the characteristics of shrinkage, when pressurized, due to the infiltration of surrounding rock, the grouting amount is larger than the 
void amount, which is generally 1.5-2 times of the void amount.

\subsection{Reduce the disturbance to the formation}

Shield construction shall be carried out continuously. When the shield machine has to stop advancing for some reason, the earth pressure on the face will cause the shield machine to retreat for a certain distance, so the protection work should be done to ensure the continuous construction. The amount of waste should be strictly controlled to avoid large settlement. It is not accurate to only use the volume of waste as the volume of discharged slag, which should be controlled by the volume of waste, the pressure of pressure chamber and the volume of excavated soil.

\section{Relationship between shield parameters and ground settlement}

Based on Shijiazhuang Metro Line 3 project, Shang Yanliang ${ }^{[8]}$ studied the relationship between cutterhead torque, cutterhead form and surface settlement value, as shown in Figure 1 and Figure 2.

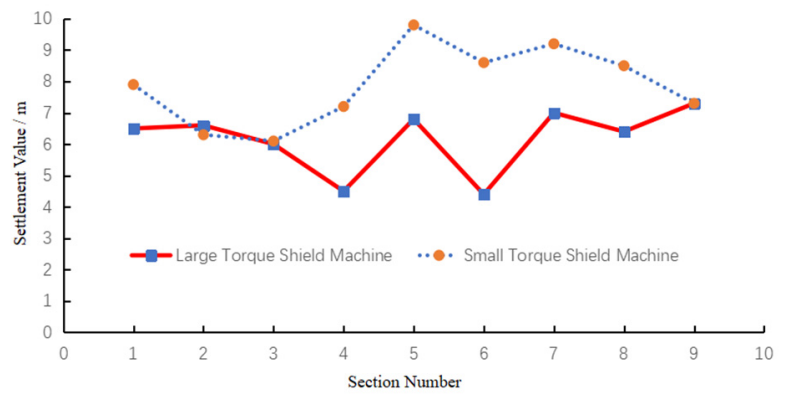

Figure 1. Settlement value of different cutterhead torque.

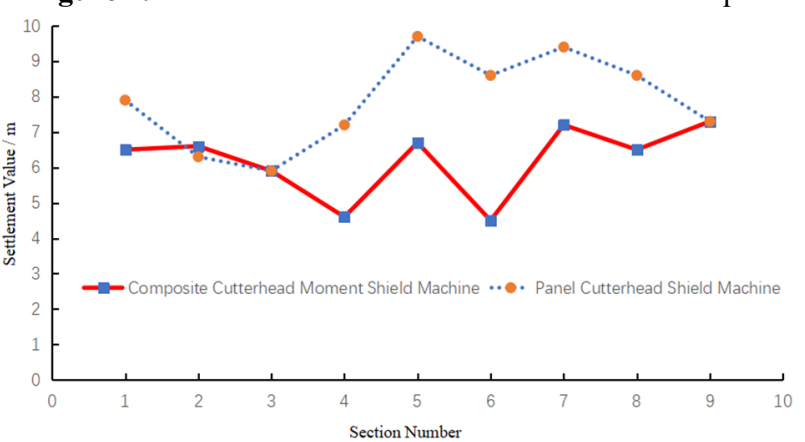

Figure 2. Settlement value of different cutterhead forms.

It can be seen from the figures that the settlement value caused by small torque excavation is $7 \mathrm{~mm} \sim 10 \mathrm{~mm}$, and that caused by large torque excavation is $11 \mathrm{~mm} \sim 14 \mathrm{~mm}$, so the settlement value caused by small torque excavation is smaller; The settlement value caused by composite cutterhead excavation is between $7 \mathrm{~mm} \sim 10 \mathrm{~mm}$, and that caused by panel cutterhead excavation is $11 \mathrm{~mm} \sim 14 \mathrm{~mm}$, so the settlement value caused by composite cutterhead excavation is smaller.

\section{Conclusion}

(1) At present, the analysis methods of shield construction mainly include empirical method, model test method, analytic method and numerical simulation method. Different methods have their own advantages and disadvantages.

(2) The main causes of ground settlement caused by shield tunnel construction are formation loss and consolidation settlement.

(3) The cutterhead torque and cutterhead form of shield machine are closely related to the ground settlement. The settlement value caused by using small cutterhead torque is less than that caused by using large cutterhead torque; The settlement caused by using composite cutterhead is less than that of using panel cutterhead.

(4) In the process of shield construction, the choice of cutter head torque and cutter head form will have an important impact on the surface settlement, so it is important to choose reasonable shield parameters

(5) There are many factors affecting the shield tunnel, but most of the research is only for a single factor, and the influence of multiple factors on the surface settlement needs to be further studied.

\section{References}

1. R.B. Peck. Deep Excavations and Tunneling in Soft Ground. C. Mexico City: State of the Art Report (1969)

2. J.H. Atkinson, D.M. Potts. Subsidence above shallow tunnels in soft Ground. J. Geotechnical Engineering. ASCE, 103:307-325 (1997)

3. I. Shinichiro, H. Toshiyuki, M. Kenji. Settlement trough above a modelshield observed in a centrifuge. Centrifuge,713 719 (1998)

4. C. Sagaseta. Analysis of undrained soil deformation due to ground geotecnique. J. Geotechnique, (37):329-333 (1987)

5. B.C. Liu, J.S. Zhang. Stochastic medium method for surface settlement caused by near surface excavation. J. Journal of rock mechanics and engineering, (04): 289-296 (1995)

6. H.B. Li, F. Jia, J. Li, S.B. Li. Key technologies for cross sea tunnel design of Dalian Metro Line 5. J. Geotechnical mechanics, 38 (S1): 395-401 (2017)

7. M.F. Du, J.Q. Man, L.B. Yi, D.D. Zhu. Study on the influence of Underpass construction at different oblique angles of a shield tunnel in Zhengzhou Metro on Railway. J. Modern tunnel technology, 57 (S1): 466-472 (2020)

8. Y.L. Shang. Study on environmental impact mechanism and monitoring and early warning of shield tunnel construction of anhydrous sand layer subway. d. Shanghai Jiaotong University (2018) 